\title{
La empresa industrial de Estevan de Antuñano (1831-1847)*
}

\section{Carlos Illades}

El 9 de febrero de 1847, el Honorable Congreso del estado de Puebla declaró "ilustre fundador de la industria fabril de la república y benemérito del estado al ciudadano coronel Estevan de Antuñano".'1 De esta manera, el poder público hacía un reconocimiento a la labor económica y política desarrollada a lo largo de más de 30 años en la ciudad de Puebla por el empresario (innovador en el cabal sentido schumpeteriano) nacido en el puerto de Veracruz. El documento legislativo, breve y escueto, fundamentaba con el siguiente argumento la distinción otorgada al prominente industrial:

V.S. fue el primero que lanzándose en medio de la incertidumbre arriesgó su fortuna y porvenir para proporcionar a su país la prosperidad y el adelanto en un ramo de tanta importancia como lo es la industria y es un deber de los pueblos reconocer los sacrificios de aquellos hombres que llevados de ideas verdaderamente filantrópicas, mejoran su posición y procuran su bienestar. .. .

Estas líneas, impregnadas de liberalismo, reconocían al Congreso como la encarnación de la voluntad popular y al moderno empresario capitalista como promotor del bien común. Se era fiel a la verdad al señalar que Antuñano había arriesgado su fortuna, actuando con audacia en medio de la incertidumbre (baste recordar los repentinos giros sufridos por la política económica y la crónica inestabilidad política del periodo); se omitía sin embargo - cosa común en actos de esa naturaleza - que las ideas "verdaderamente filantrópicas" del industrial estaban ancladas en la ruda realidad del mundo fabril, en el que se explotaba por igual a hombres, mujeres y niños y, por si fuera poco, se pagaban (al menos en La Constancia Mexicana) salarios mucho más bajos que el promedio de la industria textil nacional. ${ }^{3}$

Un mes después del reconocimiento otorgado por el Congreso, a los 55 años de edad, murió el benemérito industrial y fue enterrado en la capilla del Rosario de la iglesia de El Carmen, en la ciudad de Puebla. ${ }^{4}$

* Agradezco las observaciones de la Dra. Josefina Z. Vázquez.

1 Decreto del Honorable Congreso del Estado Libre y Soberano de Puebla, febrero 9 de 1847, Imprenta de José Ma. Macías, Puebla, 1847, en Estevan de Antuñano, Obras. Documentos para la historia de la industrialización en México, 1833-1846, prólogo de Horacio Labastida y Alejandro de Antuñano, Secretaría de Hacienda y Crédito Público, México, 1979 (en adelante DHIM), vol. 2, p. 641.

2 Loc. cit.

3 Jan Bazant, "Estudio sobre la productividad de la industria algodonera mexicana en 1843-1845 (Lucas Alamán y la revolución industrial en México)", en Colección de documentos para la historia del comercio exterior, 1962, vol. 7, pp. 29-86.

- Miguel A. Quintana, Estevan de Antuñano fundador de la industria textil en Puebla, Talleres de Impresión de Estampillas y Valores, México, 1957, vol. 1, p. 11. 
Hijo de español acaudalado, Estevan de Antuñano nació en el puerto de Veracruz el 26 de diciembre de 1792. A la edad de diez años fue enviado por su padre a España, con la intención de que se educara en el país vasco al lado de su tío Miguel de Antuñano. Según Horacio Labastida y Alejandro de Antuñano: "las fundiciones de hierro, el carbón mineral, las industrias lanares y algodoneras, la ganadería y otras agroindustrias dejaron en el joven una huella imborrable". ${ }^{5} \mathrm{Al}$ cabo de un tiempo, nuestro personaje se trasladó a Inglaterra con el objeto de completar su educación. En la isla, muy probablemente, leyó los tratados de economía de François Quesnay y de Adam Smith. En 1812 regresó a Veracruz y se dedicó al comercio en sociedad con Andrés Vallarino. Cuatro años después mudó su residencia a la ciudad de Puebla, encargándose de los negocios de su primo (Antonio Pasalagua) y de Lorenzo Carrera. Por aquellos años contrajo matrimonio con Bárbara Ávalos y Varela, cuyo abuelo era un rico hacendado, dueño de numerosas propiedades en la región de Atlixco. ${ }^{6}$

Poco se sabe sobre la vida de Antuñano. Para la década de los veinte lo encontramos plenamente integrado a la actividad económica y política de la ciudad de Puebla. En un manifiesto dirigido a Iturbide, el 21 de agosto de 1821, informándole acerca de la instalación del nuevo Tribunal del Consulado de Puebla, aparece la firma del teniente Estevan de Antuñano. ${ }^{7}$ El 11 de abril del año siguiente Antuñano figura entre los suscriptores de un documento expedido por el ayuntamiento, exhortando a la población a cooperar en el avituallamiento de la milicia nacional. ${ }^{8} \mathrm{El} 22$ de diciembre de 1823 se signó el Acta de Federación del Estado Libre de la Puebla de los Ángeles y, al calce, aparece la rúbrica de Antuñano. ${ }^{9}$

Al parecer, el intento de reconquista encabezado por Isidro Barradas agitó la fibra nacionalista de nuestro personaje. Es así que éste, en 1829, se dio a la tarea de formar el Batallón del Comercio de Puebla. ${ }^{10}$ En una carta dirigida al gobernador (6 de agosto de 1829), y publicada en El Patriota, Antuñano manifestó su indignación ante la incursión dirigida por el brigadier español:

Los esclavos de Fernando han osado poner su planta sacrílega en el sagrado territorio de la República Mexicana. . soy mexicano, y en lo particular soy poblano: mi corazón salta de indignación al oír tamaño atrevimiento y cada paso que estos caribes dan fuera de la línea del Atlántico, me parece que lo siento sobre mi existencia, y siento en mi alma el que mis notorios achaques personales, me impidan volar desde luego a escarmentarlos. $"$

5 Antuñano, op. cit., vol. 1, p. xxvir.

6 Quintana, op. cit., vol. 1, p. 11.

${ }_{7}$ Manifiesto del nuevo consulado de Puebla, a los habitantes de su provincia, con insertación de los oficios que han precedido a su instalación, Imprenta Liberal de Moreno Hermanos, Puebla, 1821, 4 pp., p. 1, Centro de Estudios de Historia de México (en adelante condumex), 1821 /Pue., 31909 (Colección Puebla).

8 El ayuntamiento a sus conciudadanos, Oficina de D. Pedro de la Rosa, Puebla, 1822, condumex, f. XuI, doc. 1293 (Colección Puebla).

${ }^{9}$ José Joaquín Izquierdo, Raudon, cirujano poblano de 1810, prefacio de Max Neuburger, Ediciones Ciencia, México, 1949, pp. 224-225.

10 Quintana, op. cit., vol. 1, p. 12.

11 El Patriota, Puebla, 14 de agosto de 1829, p. 2, Condumex, 05.72.49/Pat., 1464 (Sección hemeroteca/Colección Puebla). 
Rico al fin, Antuñano se comprometió en dicha carta a pagar los sueldos (33 pesos mensuales) de tres milicianos cívicos de infantería mientras durase la invasión. La oferta fue recibida con beneplácito por el gobierno estatal. A nombre de éste, Bernardo González agradeció el donativo consistente en 44 pesos mensuales, poniendo énfasis en que el gesto de Antuñano representaba un ejemplo a seguir por los ciudadanos poblanos. ${ }^{12}$ Este halago, al parecer, le costó a Estevan de Antuñano el pago de un cuarto soldado. Por aquellas fechas Antuñano ya ostentaba el rango de coronel del batallón 21 de la milicia nacional local.13

La actividad pública de Antuñano no se redujo a brindar apoyo al gobierno. Hacia 1830 se fundó en la ciudad de Puebla la Sociedad Patriótica para el Fomento de las Artes, ocupando nuestro personaje $>$ el cargo de tesorero dentro de la junta directiva. La nueva entidad era una sociedad por acciones, constituida con el fin de apoyar a los artesanos locales mediante la introducción de herramientas y máquinas que sirvieran para incrementar la productividad y reducir los costos de producción. ${ }^{14}$ Tres años después, Antuñano publicó algunas reflexiones sobre la necesidad de favorecer el desarrollo de las artes, las cuales podrían dar razón de su interés por participar en la Sociedad Patriótica:

. .la nación ya necesita adelantar en las artes, como corresponde al nuevo papel que representa en el mundo; para un colono basta un grosero sucio vestido, para un ciudadano de una república civilizada, son necesarios otros adornos: los gastos públicos se han incrementado excesivamente, y un pueblo corto y pobre no puede reportarlos, por esto es menester enriquecerlo y aumentarlo. ${ }^{15}$

En 1831 Antuñano adquirió por 1000 pesos 20 acciones de la Sociedad Patriótica, cediendo por dos años sus utilidades al hospicio de la capital poblana. ${ }^{16}$ Para entonces, estando en paz con el gobierno, con sus conciudadanos y con Dios, Estevan de Antuñano se entregó en cuerpo y alma a la edificación de su primera fábrica de hilados de algodón: La Constancia Mexicana.

A lo largo de las siguientes páginas trataremos de explorar las vicisitudes sufridas por las fábricas de Antuñano, ver la manera como funcionaban, la mano de obra que empleaban y ubicarlas en el contexto de la industria textil poblana. Posteriormente, intentaremos

12 El Patriota, Puebla, 12 de agosto de 1829, p. 3, condumex, 05.72.49/Pat., 1464 (Sección hemeroteca/Colección Puebla).

13 El Patriota, Puebla, 9 de septiembre de 1829, p. 2, condumex, 05.72.49/Pat., 1464 (Sección hemeroteca/Colección Puebla).

14 Un año antes de la fundación de la Sociedad Patriótica, el Congreso de Puebla rechazó el proyecto presentado por José Ma. Godoy, Guillermo Dollar y Jorge Winterton. Dicho proyecto proponia el establecimiento de telares mecánicos en diversas partes de la república, a cambio de que los individuos antes citados obtuvieran el monopolio de la importación de textiles extranjeros durante un periodo de siete años. Luis Chávez Orozco, Historia económica y social de México. Ensayo de interpretación, Ediciones Botas, México, 1938, p. 119.

15 Antuñano, Industria fabril, el algodón, pan de los pobres y origen de las virtudes de los mexicanos, Oficina del Hospital de San Pedro, Puebla, 1833 (DHIM, vol. 1, p. 55). Para una relación de las obras de Antuñano véase José Miguel Quintana, "Bibliografía de Estevan de Antuñano", Revista de la Universidad de Puebla, núm. 5, mayo de 1944, pp. 37-55.

16 Quintana, Estevan..., op. cit., vol. 2, p. 75. 
mostrar los problemas derivados de la escasez de algodón y la manera como el industrial trató de solucionarlos. En el epílogo, seguiremos el proceso que permitió a los agiotistas apoderarse progresivamente de los establecimientos fabriles de Estevan de Antuñano.

\section{La Constancia Mexicana}

. . la ignorancia produce pobreza y revolución, difícil es que un hombre ignorante deje de ser pobre; porque el adquirir riqueza es obra de los conocimientos: con dificultad el que es ignorante y pobre, podrá prestar garantía de quietud: porque la quietud es producida por la comodidad y la ilustración. La pobreza engendra ignorancia y revolución; sin productos o sea sin capital, no se puede adquirir educación, que proporciona el saber, y éste es el mejor antemural, tras el cual se forma y fortifica el espíritu público, contra las insidias de los revoltosos. La revolución necesariamente acarrea la pobreza y la ignorancia. . . cada una de estas penalidades es a su vez causa y efecto de las otras; pero indudablemente, ellas forman el combustible encendido que nos abrasa. ${ }^{17}$

Con esta cadena de silogismos, Antuñano pretendía demostrar que la mejor manera - y quizá la única- de sacar al país del atolladero en que se encontraba era promoviendo el desarrollo industrial. México ya había logrado la independencia política, pero ahora resultaba apremiante obtener la emancipación industrial. Dolores fue la cuna de la primera, Puebla lo podía ser de la segunda.

Al círculo vicioso relatado en la cita, el industrial oponía el siguiente razonamiento: "las máquinas modernas establecidas en México y manejadas por mexicanos, ocuparían a nuestros tejedores. . . fomentarían nuestra agricultura de algodón. . . conservarán en el país muchos millones de pesos, cuya circulación hará prosperar todos los ramos... abaratarán los tejidos, y con ello aliviarán a las otras clases pobres. .."18

Para Antuñano resultaba imprescindible ocupar en actividades productivas a la gente ociosa y generar riqueza, por ello la asociación entre capital y trabajo era necesaria. El empleo alejaría a sectores amplios de la población de las revueltas políticas y desterraría del país el pernicioso "espíritu de partido". Armado con estas convicciones Antuñano emprendió su labor industrial.

En su casa, tiempo antes de iniciar la construcción de su primera fábrica, el industrial en ciernes acondicionó un pequeño laboratorio experimental, con el objeto de analizar fibras, tinturas, materiales y artificios similares a los que conoció en España. A mediados de 1831 Estevan de Antuñano -en sociedad con Gumersindo Saviñón- comenzó la construcción de La Constancia Mexicana. Para tal fin adquirieron una hacienda próxima a la ciudad y su condición de pio-

17 Antuñano, Memoria breve de la industria manufacturera de México, desde el año de 1821 hasta el presente; señalando los motivos de su aniquilamiento, los efectos que éste ha producido sobre la moral y la riqueza, y el remedio análogo para poner a nuestra industria en un estado animado, Oficina del Hospital de San Pedro, Puebla, 1835, pp. 1-2 (DHIM, vol. 1, pp. 223-224).

- 18 Antuñano, Industria. .., op. cit., p. 62 (DHIM, vol. 1, p. 104). Antuñano, incluso, llegó a plantear la necesidad de que en México se establecieran fábricas que elaboraran herramientas. Charles A. Hale, "Alamán, Antuñano y la continuidad del liberalismo", Historia Mexicana, vol. XI, núm. 42, octubre-diciembre de 1961, pp. 224245. 
neros les permitió ubicarse en el lugar más propicio para aprovechar las aguas del río Atoyac, indispensables para el funcionamiento de las máquinas que proyectaban instalar. ${ }^{19}$

El proceso de montar la fábrica duró cerca de tres años y medio y resultó complicado en extremo. Las fortunas personales de Antuñano y Saviñón se agotaron pronto y la instalación de la fábrica irritó a ciertos segmentos de la población. Según narra Miguel A. Quintana, en el año de 1832 hubo tentativas de asesinar al propio Antuñano y, a finales de año, "cuando Santa Anna entró triunfante a Puebla en una de tantas revoluciones, [Antuñano] fue llevado preso ante él bajo la acusación de pretender la ruina de las hilanderas y los tejedores". ${ }^{20}$ A estos problemas y conflictos hicieron alusión Antuñano y Saviñón en un folleto publicado en 1835:

. . por este mismo tiempo la envidia, la ignorancia y todas las pasiones innobles combatieron nuestra empresa, ya imaginándola perjudicial a la industria, ridiculizándola como impracticable, y ya por último dirigida a unos fines poco humanos: en una palabra, reducidos nuestros hijos a no asistir al templo por falta de calzado, nos vimos perseguidos como unos hombres orgullosos, despreciados como ignorantes, y acusados y perseguidos como perjudiciales... ${ }^{21}$

La ayuda del gobierno fue fundamental para sacar a flote la empresa industrial. En diciembre de 1832 , la junta directiva del Banco de Avío decidió asignar a La Constancia Mexicana la maquinaria que estaba destinada a la Compañía Industrial de Puebla. Hacia finales de 1833 Antuñano recibió un préstamo por 36000 pesos, con el cual pudo rescatar la maquinaria que tiempo atrás había adquirido en Estados Unidos y que, por falta de pago, no había podido recoger aún. En 1834 fue aprobado un préstamo por 60000 pesos y, al año siguiente, se le otorgó otro por $30000 .^{22}$

Pagar los adeudos contraídos con el Banco de Avío no fue cosa fácil. En una carta dirigida al diputado Carlos María de Bustamante, Antuñano escribía con desazón que su deuda con la banca de fomento:

... nos aflige y mortifica extraordinariamente exigiendo los réditos de los capitales que nos ministró. De tener que pagarlos le sigue indispensablemente la necesidad de cerrar la fábrica con perjuicio de muchísimas familias, del progreso de la industria y del decoro de la nación; sería para nosotros lo más amargo. Para evitarlo y ver cómo podíamos ir sosteniendo este benéfico establecimiento interior. . elevamos el día 24 de octubre próximo pasado, una exposición al Supremo Gobierno solicitando que se nos dispensaren los réditos y plazos de las cantidades que el banco nos ministró hasta tanto el gobierno pudiese poner en ejecución la prohibición decretada que nos comprometió. ${ }^{23}$

19 Antuñano, Obras. . ., p. XxIX; Bazant, Antonio Haro y Tamariz y sus aventuras políticas, 1811-1869, El Colegio de México, México, 1985, p. 32.

20 Quintana, Estevan..., vol. 1, p. 47.

21 Estevan de Antuñano y Gumesindo Saviñón, Exposición respetuosa que los que suscriben elevan a las soberanas cámaras de la Unión sobre la prohibición de artefactos gordos de algodón extranjeros, Imprenta del C. José Ma. Campos, Puebla, 1835, p. 4 (DHIM, vol. 1, p. 212).

22 Robert A. Potash, El Banco de Avio de México. El fomento de la industria I821-1846, Salazar y José R. Rodríguez, Fondo de Cultura Económica, México, 1986, 2a. ed., pp. 107 y 121. Antuñano y Saviñón, op. cit., p. 4 (DHIM, vol. 1, p. 212).

23 Carta de Antuñano a Carlos Ma. de Bustamante, Puebla, 7 de febrero de 1836 (DHIM, vol. 2, pp. 553-554). Antuñano se refiere a la ley del 22 de mayo de 1829. 
No fue sino hasta 1838, ya aplicada la prohibición de importar hilo e hilaza de algodón, cuando Antuñano pudo terminar de finiquitar su adeudo con el Banco de Avío. ${ }^{24}$

Pero volvamos al relato de los obstáculos que dificultaron la instalación de la fábrica. El principal problema fueron los excesivos gastos y los imprevistos. Los técnicos extranjeros que vinieron a instalar las máquinas y capacitar a los operarios mexicanos cobraron salarios muy altos y, por lo general, no representaron una ayuda significativa para los propietarios de la fábrica. Por último, el cólera hizo estragos entre los lugareños, generándole a los dueños del establecimiento fabril gastos extraordinarios. ${ }^{25} \mathrm{~A}$ pesar de las dificultades y obstáculos, el 7 de enero de 1835 La Constancia Mexicana abrió sus puertas.

Puebla resultaba un buen lugar para el establecimiento de fábricas textiles cuando menos por dos razones: su ubicación estratégica al encontrarse situada entre Veracruz y la ciudad de México y por la amplia tradición textil que poseían los artesanos de la región. ${ }^{26}$ Un cálculo conservador indica que hacia 1830 la capital de la entidad tenía aproximadamente 40000 habitantes. ${ }^{27}$ La población ocupada era del orden de 14000 personas y cerca de diez por ciento de ésta la conformaban tejedores e hilanderos. Por cada tres tejedores había un hilandero en la ciudad. ${ }^{28}$

Cuando comenzó a funcionar, La Constancia Mexicana tenía en operación 2500 husos, contaba con dos máquinas despepitadoras ubicadas en Veracruz y daba trabajo a 120 operarios que hilaban 350 libras de algodón al día. En un principio la factoría sólo estaba equipada con maquinaria para hilar, pero para 1843 ya se fabricaban también tejidos. ${ }^{29}$

La mecanización industrial no afectó por igual al artesanado textil poblano. Hacia mediados de siglo, como señalan Contreras y Grosso, "se puede decir que las hilanderas habían desaparecido; mientras en 1830 generaban $13.80 \%$ ( 468 personas) del empleo, para 1842-1853 apenas alcanzaban $0.20 \%$ ( 4 personas). Estos fenómenos eran ya los primeros resultados de la constitución de la 'nueva industria textil" ". ${ }^{30}$ Los tejedores, por su parte, no sufrieron durante un

24 Potash, op. cit., p. 156.

${ }^{25}$ Ibid., p. 227. Antuñano y Saviñón, op. cit., pp. 4-5 (DHIM, vol. 1, pp. 212-213).

${ }^{26}$ Bazant, "Estudio. . .", p. 69. Jorge González Angulo y Roberto Sandoval Zarauz señalan que a comienzos del siglo xIx, Puebla ocupaba a cerca de 25000 personas en el ramo textil. "Los trabajadores industriales en Nueva España, 1750-1810", en Enrique Florescano et al., De la colonia al imperio, Siglo XXI Editores, México, 1981, 2a. ed., pp. 173-238 (La Clase Obrera en la Historia de México, 1).

${ }^{27}$ Carlos Contreras y Juan Carlos Grosso, "La estructura ocupacional y productiva de la ciudad de Puebla en la primera mitad del siglo xIx", Ludmila Borisovna et al., Puebla en el siglo xix. Contribución al estudio de su historia. IAP, Puebla, 1983, pp. 111-176. Dicho cálculo se le atribuye a Javier de la Peña.

28 lbid., pp. 129 y 134.

${ }^{29}$ Antuñano y Saviñón, op. cit., p. 6 (DHIM, vol. 1, p. 214). Bazant, "Estudio. . .", pp. 61 y 69 . Antuñano afirmaba que en su fábrica sólo se elaboraba hilaza del número 21 para abajo, Breve memoria del estado que guarda la fábrica de hilados de algodón La Constancia Mexicana y la industria de este ramo, Oficina del Hospital de San Pedro, Puebla, 1837, 24 pp., p. 11 (DHIm, vol. 1, p. 249). Dawn Keremitsis señala que hacia mediados del siglo XIX a lo sumo habría seis máquinas despepitadoras en todo el país, La industria textil mexicana en el siglo x/x, stP, México, 1973, pp. 24-25 (stP/Setentas, 67).

30 Contreras y Grosso, op. cit., p. 139. 
buen tiempo con la mecanización industrial, incluso resultaron parcialmente beneficiados por contar ahora con un abastecimiento regular de materia prima, proporcionada por las fábricas de hilados. El propio Estevan de Antuñano relataba con alegría en 1837 que "más de 400 familias se mantienen en Puebla, y en algunos puntos de su departamento, por tejer el hilo de La Constancia. . ."31

No obstante haber sido un escritor prolijo, Antuñano dejó sólo escasas referencias al funcionamiento interno de su fábrica. En un opúsculo publicado en 1843, el industrial afirmaba que en La Constancia Mexicana la jornada laboral duraba 16 horas, teniendo los operarios hora y media para comer y descansar. ${ }^{32}$ También sabemos con certeza que Antuñano empleaba fuerza de trabajo infantil y femenina en su factoría. En un folleto redactado en 1837, el industrial residente en Puebla esgrimió las ventajas económicas y morales que conllevaba el trabajo de mujeres y niños. Brevemente las podemos resumir así: 1) Se fortalecía el ingreso familiar; 2) se elevaba el nivel moral de la familia y se incrementaba su cohesión; 3 ) se podía acceder a mejores viviendas, con el consecuente reforzamiento de las condiciones de higiene y salud familiares. ${ }^{33} \mathrm{El}$ púdico y benévolo fabricante concluía su escrito con el siguiente razonamiento:

Quizá algunas personas timoratas encontrarán peligros morales en la concurrencia asidua de ambos sexos a un mismo lugar, pero reflexionen, que más peligro corre en su casa una mujer joven, ociosa y sola, por las separaciones que dos o tres veces al dia tengan que hacer sus mayores, o que ella tenga que salir, que en un lugar, bajo la vista de sus deudos, muy concurrido y muy cuidado por los directores y maestros, que comúnmente han de ser personas de juicio, y por último un lugar donde nadie pueda estar ocioso ni separarse de él, porque las máquinas para andar bien en sus operaciones progresivas, no permiten largas paradas, ni distracciones. ${ }^{34}$

Es posible que el empleo de mano de obra infantil y femenina haya permitido a Estevan de Antuñano pagar salarios bajos. En otro lugar del escrito que acabamos de citar, el industrial incluye algunos datos sobre las familias que trabajaban en La Constancia Mexicana, en donde queda asentado que laboraban en ésta niños de seis y siete años de edad. ${ }^{35}$ No se aclara en el texto si vivían o no los trabajadores

31 Antuñano, Breve..., p. 8 (DHm, vol. 1., p. 246). Juan Felipe Leal y José Woldenberg, Del estado liberal a los inicios de la dictadura porfirista (1867-1884), Siglo XXI Editores, México, 1980, p. 127 (La Clase Obrera en la Historia de México, 2), Grosso, "Eștructura productiva y fuerza de trabajo en el área del municipio de Puebla (siglo XIX)", en Mario Cerutti (coordinador), El siglo xIX en México, Claves Latinoamericanas, México, 1985, pp. 200-239.

32 Antuñano, Documentos para la historia de la industria algodonera de México, en lo fabril y en lo agricola, o sea narraciones y cálculos estadísticos sobre ella, Imprenta de Juan N. del Valle, Puebla, 1843, cuadros estadisticos, p. 13 (DHIM, vol. 1, p. 5(9).

$3 s$ Antuñano, Ventajas politicas, civiles, fabriles y domésticas, que por dar ocupación también a las mujeres en las fábricas de maquinaria moderna que se están lezantando en México, deben recibirse, Oficina del Hospital de San Pedro, Puebla, 1837, pp. 3-6 (1)Hu, vol. 1, pp. 267-270).

34 Ibid., p. 6 (DHIM, vol. 1, p. 270).

35 Ibid., pp. 7-8 (DHM, vol. 1, pp. 271-272). Bazant, después de realizar un estudio comparativo de las fábricas textiles poblanas que funcionaban en 1843, demostró que Antuñano pagaba salarios más bajos que sus competidores, véase "Estudio. . ", p. 71 e "Industria algodonera poblana de 1800-1843 en números", Historia Mexicana, vol. XIV, núm. 53, julio-septiembre de 1964, pp. 132-133 y 140-141. 
er las inmediaciones de la fábrica (situada a legua y media de la ciu dad de Puebla), hecho que se volvió común en las factorías de las dér adas posteriores. ${ }^{36}$

\section{La industria y su entorno}

Los productos textiles nacionales, por lo general, estaban destinados a los consumidores de bajos recursos. Cuando la situación económica no era crítica, resultaba común que la gente comprara manta para confeccionarse un traje al año. El consumo de manta, principal tela elaborada en el país, dependía básicamente de la estabilidad económica y, para incrementar su demanda, era indispensable que creciera la población. ${ }^{37}$ La gente adinerada, por su parte, compraba textiles extranjeros internados legal o ilegalmente en el país. En suma, la rigidez de la demanda doméstica representó un obstáculo para la expansión de la industria textil nacional.

Otro problema de la naciente industria, que afectó no sólo a ésta sino al conjunto de la economía, fue la precariedad de los transportes. La carencia de medios de transporte expeditos dificultó en buena medida la conformación del mercado interno. Los textiles, por ejemplo, se vendían en los mercados locales y no llegaban a consumidores situados lejos de las unidades productivas. De la misma manera, las materias primas y los insumos tenían que recorrer caminos difíciles y tortuosos antes de llegar a los centros fabriles. ${ }^{38}$

Los impuestos al comercio exterior representaron a lo largo del siglo xix el principal ingreso fiscal del estado. Por tal motivo, la aplicación de políticas de fomento industrial - que para ser eficaces necesariamente tenían que ir a la par de la adopción de medidas proteccionistas e incluso de prohibiciones - corrían a contrapelo de las necesidades financieras del aparato estatal. Sobre estos tópicos resulta interesante la opinión emitida por Antuñano en el año de 1838, quien juzgaba indispensable para resolver los problemas del erario público la adopción de las siguientes medidas (por lo demás de gran actualidad): reducción del gasto público, fomento a la industria, contratar préstamos a plazos largos y, por último, formar el tesoro público sobre la base de la industria nacional. ${ }^{39} \mathrm{El}$ industrial concluía tajante: si la hacienda no se organiza "principal y directamente sobre la industria de los mexicanos, que es el único seguro

36 Alejandra Moreno Toscano, "Los trabajadores y el proyecto de industrialización (1810-1867)", en Enrique Florescano et al., De la colonia al imperio, Siglo XXI Editores, México, 1981, 2a. ed., pp. 302-350 (La Clase Obrera en la Historia de México, 1).

37 Keremitsis, op. cit., pp. 28-29.

38 John $\mathrm{H}$. Coatsworth señala que "la independencia liberó al país de la fuente de las políticas, leyes e instituciones que inhibían a la actividad empresarial. La tecnología ferrocarrilera se desarrolló en la década de 1830 y podría haber sido importada fácilmente hacia la década siguiente. Pero al contrario de esto, México penetró en medio siglo de luchas políticas, sociales e internacionales. El colapso del gobierno estable anuló los efectos potencialmenté positivos de los pocos cambios que acompañaron a la independencia, y privó tanto al nuevo gobierno como al sector privado de los recursos necesarios para mejorar los transportes", "Caracteristicas generales de la economía mexicana en el siglo XIX", en Enrique Florescano (comp.), Ensayos sobre el desarrollo económico de México y América Latina (1500-1975), Fondo de Cultura Económica, México, 1979, pp. 170-186.

39 Antuñano, Economia política en México. Ideas vagas para un nuevo plan de la Hacienda Priblica, Imprenta Antigua en el Portal de las Flores, Puebla, 1838, p. 3 (DHin, vol. 1, p. 363). 
manantial de riqueza para el erario, mientras así no se efectúe, no consumaremos nuestra independencia política".40

$\mathrm{El}$ primer intento radical de proteger la industria textil nacional fue la ley del 22 de mayo de 1829 , promulgada durante el gobierno de Vicente Guerrero. La disposición jurídica prohibía la importación de textiles baratos; sin embargo, las necesidades económicas del propio gobierno de Guerrero, agudizadas por la invasión del general Barradas, primero, y por la rebelión de Anastasio Bustamante, después, impidieron la ejecución de lo planteado en la ley. ${ }^{41} \mathrm{Al}$ año siguiente, con la fundación del Banco de Avío y el marco jurídico que lo acompañó, quedó asentado que para reunir los fondos de la institución (un millón de pesos) se permitiría la importación de los textiles prohibidos por la ley del 22 de enero. Una quinta parte de los gravámenes aplicados a los textiles extranjeros iría a parar a las arcas del banco de fomento.

Artesanos y fabricantes actuaban con la convicción de que tan pronto el Banco de Avío reuniera el fondo que la ley le había asignado, entrarian en vigor las disposiciones prohibitivas de 1829 . Hacia el año de 1835 las voces de estos grupos sociales cobraron fuerza en la Cámara de Diputados, consiguiendo, incluso, que la Comisión de Industria de la misma emitiera un dictamen que prohibiera la introducción de toda clase de hilazas extranjeras de algodón (artículo 1), así como la importación de mantas blancas, estampadas y trigueñas (artículo 2). En el artículo 7 se decía que se derogarian "las mercantiles que se opongan en todo o en parte a la presente". ${ }^{42} \mathrm{Se}$ asumía, por tanto, que el fondo del Banco de Avío ya estaba constituido. Sobre el particular, Antuñano tenía la siguiente divisa:

En hacer elección acertada de lo que se pueda dejar introducir y bajo qué gravámenes; lo que se debe prohibir y por qué tiempo, y lo que convenga dejar entrar libremente y aun con premio, y además por qué puntos deben únicamente hacerse las introducciones, se cifra la más interesante parte de la ciencia económico-política de un hombre de Estado. ${ }^{43}$

Pero, como relata Potash, desde el año de 1833 la tesorería absorbía los fondos aduanales destinados al Banco de Avío y, por ende, el gobierno federal hizo todo lo posible porque no se ejecutaran las leyes prohibicionistas. El dictamen de la Comisión de Industria fue aprobado por la Cámara de Diputados; sin embargo, el Senado no hizo lo propio. En lugar de ello, elaboró una contrapropuesta que contemplaba la ampliación de los fondos del banco de fomento (pasando de un millón a 1.5 millones de pesos). Los diputados aceptaron la nueva redacción, convirtiéndose en ley el 23 de mayo de $1835 .^{44}$

${ }^{40}$ Ibid., p. 12 (DHм, vol. 1, p 372). Jesús Reyes Heroles, de manera convincente, expuso cómo la política quedaba subordinada a la economía en el pensamiento de Antuñano, "El caso Antuñano", Historia Mexicana, vol. XI, núm. 42(2), octubre-diciembre de 1961, p. 255.

41 Potash, op. cil., p. 66.

42 Dictamen de la Comisión de Industria sobre la prohibición de hilazas y tejidos de algodón del extranjero. Presentado en la Cámara de Diputados el día 27 de marzo de 1835, Imprenta de Santiago Pérez, México, 1835, pp. 13-14. CON1) 'MEX, 677.2.72/M-CD, 39913 (Sección folletos).

43 Antuñano, Comercio exterior de México. Primera parte, Imprenta del Hospital de San Pedro, Puebla, 1837, p. 2 (1)HM, vol. 1, p. 300).

44 Potash, op. cil., pp. 130-136. 
No fue sino hasta 1837 cuando los fabricantes textiles recibieron del gobierno la ayuda que esperaban. Es así que el 11 de marzo se promulgó un nuevo Arancel General de Aduanas Marítimas que prohibió la importación; entre otros muchos productos, de hilo e hilaza de algodón de todo tipo y número, de algunos artículos textiles y ciertas prendas de vestir. ${ }^{45}$

Con la expedición del nuevo arancel, Antuñano y los otros fabricantes del ramo textil podían dormir tranquilos, el giro industrial había quedado protegido del devastador efecto de la competencia extranjera. Sin embargo, la quietud duró poco tiempo. La escasez de algodón - desde 1836 no se podía importar la fibra en rama- se hizo patente a finales de la década y las fábricas resintieron sus efectos. Antuñano, como siempre, recurrió a su pluma para defender sus amenazados intereses.

\section{El algodón}

Casi al mismo tiempo que se prohibió la importación de hilo e hilaza de algodón, Antuñano sufrió la pérdida de un embarque de maquinaria. En una carta dirigida a Lucas Alamán, el industrial escribía con dolor:

. . que la fragata paquete de Estados Unidos naufragó en las costas de la Florida y que en ella ha perdido mi casa una grande y selecta colección de maquinaria de hilados y también una máquina de vapor de 20 caba. llos que se destinaba a mover en la costa de Veracruz tres máquinas de despepitar algodón; asimismo se ha perdido en otro paquete otra máquina de hilar que iba destinada a Querétaro y otra de 1000 malacates habilitadas para esta ciudad. ${ }^{46}$

En 1837 ocurrió otro evento importante que tuvo consecuencias significativas en el futuro inmediato: los señores Dionisio José de Velasco, Ciriaco Marlón y Andrés Vallarino iniciaron la construcción de la que sería la otra gran fábrica textil poblana: El Patriotismo Mexicano. Fue precisamente el propio Antuñano el que vendió por el precio de 35000 pesos plata el terreno donde se instaló la nueva empresa, la cual proyectaba instalar 3840 malacates. ${ }^{47}$ La

45 Manuel Dublán y José Ma. Lozano, Legislación mexicana o colección completa de las disposiciones legislativas expedidas desde la independencia de la república, s.e., México, 1876-1904, vol. 3, pp. 313-314. Dos meses antes Antuñano hizo la siguiente propuesta: "Primero: prohibir la entrada de todas las telas extranjeras de algodones, desde la calidad de madapollan, inclusive, hasta las más gordas trigueñas, blancas y pintadas. Segundo: permitir la entrada, por sólo uno o dos puertos los más vigilables, de hilaza de algodón desde el número 21 para arriba, bajo el derecho que hoy señala el arancel, por el término de tres años prefijos. Este permiso podrá hacerse por medio de privilegios o patentes, por determinadas cantidades o rematados en subasta pública, por cuyo medio sería fácil sacar el derecho íntegro y también el importe del privilegio. Tercero: impedir la entrada del número 21 para abajo, sea cual fuere la forma que traiga el hilado o expresamente las telas unidas. Cuarto: imponer un moderado e igual derecho en todos los departamentos a las mantas del país", "Breve. . ", pp. 21-22 (DHIM, vol. 1, pp. 258-259).

46 Carta de Antuñano a Lucas Alamán, Puebla, 22 de marzo de 1837 (DHIM, vol. 2, p. 554).

${ }^{47}$ Carmen Aguirre y Alberto Carabarín, "Propietarios de la industria textil de Puebla en el siglo xIx: Dionisio Velasco y Pedro Berges de Zúñiga", en Ludmila Borisovna et al., op. cit., pp. 177-224. 
factoría se situó a un kilómetro de distancia de La Constancia Mexicana, en un punto más bajo y, por tanto, menos propicio para beneficiarse de la caída de agua del río. ${ }^{48}$ Pero, si bien es cierto que El Patriotismo Mexicano tenía esta desventaja, poseía un punto a favor tan o más importante que el anterior y que resultó decisivo durante los primeros años de la década siguiente: tenía garantizado un abasto regular de algodón, ya que uno de sus dueños (Dionisio José de Velasco) estaba casado con la hija de un prominente cosechero de algodón de Tlacotalpan. ${ }^{49}$

¿Por qué armaría Antuñano a sus futuros enemigos? Pensamos que por lo menos hubo dos factores que motivaron la decisión de vender los terrenos. El primero, quizá más importante, lo constituyó la necesidad de obtener fondos para saldar la deuda con el Banco de Avío. El segundo, de orden ideológico, obedecía a que Antuñano creía realmente en las bondades de la competencia capitalista; rechazaba la importación de textiles extranjeros porque eran fabricados en condiciones muy superiores a las nacionales y, por tanto, la competencia resultaba desigual e injusta. Las manufacturas nacionales, en cambio, al elaborarse en condiciones de producción semejantes otorgaban iguales posibilidades a los fabricantes, impulsando esta competencia sana el desarrollo del conjunto de la economía. La cruda realidad, sin embargo, enfrentó a Estevan de Antuñano con los propietarios de El Patriotismo Mexicano. En una carta dirigida a Lucas Alamán, Antuñano habla de "cierta casa fabricante enemiga mía". 50

Los últimos años de la década sirvieron para hacer crecer la infraestructura de La Constancia Mexicana y reforzar el entusiasmo de su propietario. Para 1838 el establecimiento contaba con 3840 husos y, como relatara Antuñano:

Los 300 operarios de ambos sexos que se ocupan en el hilado, trabajan divididos en dos compañías que alternan día y noche; sus costumbres son irreprensibles; la perseverancia en el trabajo es su divisa; sólo los domingos se exceptúan de él; el aseo en su persona los días festivos, y los modales urbanos han hecho progresos; todos son voluntarios, y la puerta está abierta a todas horas, los operarios de La Constancia Mexicana están desmintiendo las atroces imputaciones que se hacían al carácter mexicano. $^{51}$

Dos años después, la factoría de Antuñano tenía en movimiento 7500 malacates; poseía 90 telares de poder y trabajaban en ella 600 operarios. ${ }^{52}$ La capacidad de la fábrica había llegado a su punto más alto; sin embargo, para desgracia de su propietario, en ese mismo año de 1840 se empezó a sentir con agudeza la escasez de algodón.

48 Bazant, Antonio..., p. 32.

49 Aguirre y Carabarín, op. cit., p. 179.

50 Carta de Antuñano a Lucas Alamán, Puebla, 1 de marzo de 1837 (DHIM, vol. 2, p. 585).

${ }^{51}$ Antuñano, Economia política en México. Ideas..., pp. 2-3 (DHim, vol. 1, pp. 304-305).

52 Antuñano, Teoria fundamental de la industria de algodones en México, por exposición que al soberano Congreso Nacional, del que suscribe, probando el próximo peligro que amenaza al ramo de algodones, por la subsistencia de la ley que prohíbe la importación de algodón extranjero en rama, y prevenir para el futuro este fatal acontecimiento, Imprenta Antigua del Portal de las Flores, Puebla, 1840, p. 9 (DHIM, vol. 1, p. 399). 
Dawn Keremitsis calcula que para 1845 el algodón producido en el país tan sólo cubría la cuarta parte de la demanda nacional. ${ }^{53} \mathrm{Se}$ puede afirmar, por tanto, que la prohibición de importar algodón en rama tarde o temprano iba a provocar una crisis dentro del ramo de las manufacturas textiles. Durante 1841-42, la cosecha de algodón en Veracruz (principal departamento productor de la fibra) había sido del orden de 36000 y 30000 quintales, respectivamente. Para el año de 1843 se presumía que no rebasaría los $18000 .{ }^{54}$ Por esas fechas, Antuñano calculaba que las hilaturas nacionales ocupaban anualmente 480000 arrobas de algodón limpio (120000 quintales) y, las poblanas, 96000 arrobas (24000 quintales). ${ }^{55}$ En el mejor de los casos, el algodón jarocho sólo alcanzaba para satisfacer la demanda poblana.

La reducida oferta de algodón provocó dos fenómenos: el incremento de su precio y la subutilización de la capacidad instalada de los establecimientos fabriles. Al primer problema aludió Antuñano en un opúsculo publicado en 1840:

\begin{abstract}
Hace seis meses valía el algodón en rama en Puebla seis pesos la arroba, hoy quieren más de diez pesos por el mismo peso, y quién sabe cuánto más llegará a valer antes de la nueva cosecha que será en abril y mayo, y que se empezará a recibir en Puebla hasta julio, esta enorme suba del algodón, es preciso que cause un gran trastorno a toda la industria. Hoy un dueño de fábrica de hilo necesita un capital casi doble para algodones. ${ }^{56}$
\end{abstract}

El fantasma del cierre de fábricas recorrió la industria textil durante varios años. En un remitido publicado en un periódico de la ciudad de México, Antuñano trataba de tranquilizar a los trabajadores amenazados con la posibilidad del desempleo y, de paso, exhibir sus cualidades morales:

... debéis saber asimismo, que en los telares en que os ocupáis, estoy perdiendo diariamente de doce a catorce pesos, y que si los he conservado en operación, ha sido con el noble y doble objeto, primero: de mantener a mis expensas, puede decirse, 100 personas pobres, que os ocupáis en ellos, y otras 200 o más, que directamente dependen de vosotros; segundo, el de adelantar y establecer bien en el país el arte de tejer con perfección y economía... .57

Para colmo de males, en 1841 , durante corto tiempo, se permitió introducir al país hilaza extranjera. ${ }^{58}$

${ }^{53}$ Keremitsis, op. cit., p. 67.

${ }^{5}$ Luis Chávez Orozco y Enrique Florescano, Agricultura e industria textil de Veracruz, siglo XIX, Universidad Veracruzana, Xalapa, 1965, p. 250 (Fuentes para la Historia Económica y Social de Veracruz, 1).

${ }_{55}$ Antuñano, Documentos. ... p. 4 (DHIM, vol. 1, p. 510).

${ }^{56}$ Antuñano, Economia politica en México. Raciocinios para un plan para repeler noblemente la importación de algodones extranjeros, en cualquier forma, por el desenvolvimiento violento de la industria nacional de la misma especie, fundando dicho desenvolvimiento sobre la baratura y abundancia del algodón en rama, Imprenta Antigua en el Portal de las Flores, Puebla, 1840, p. 7 (DHIM, vol. 1, p. 427).

57 Diario del Gobierno de la República Mexicana, México, 3 de julio de 1841 (DHIM, vol. 2, p. 21).

58 Antuñano, Anuario interesante para la propiedad y seguridad de la industria nacional de México en el ramo de algodones, Imprenta del Portal de las Flores, Puebla, 1841, p. 2 (DHIM, vol. 1, p. 432). El presidente Mariano Arista fue quien autorizó la citada importación. 
A pesar de la crisis industrial provocada por la escasez de materia prima, Antuñano pudo salir adelante durante algún tiempo gracias a que su fábrica era la que tenía, en la región, el mayor volumen de utilidades. Jan Bazant ha calculado que en cada pieza de manta La Constancia Mexicana obtenía una ganancia neta de $20 \%$, en tanto que la utilidad bruta semanal de la factoría se aproximaba a los 3000 pesos. ${ }^{59}$ Esta puede ser la razón que lo motivó, no obstante el alto precio del algodón, a poner en marcha a principios de 1843 una nueva fábrica (La Economía Mexicana). El establecimiento contaba con 4406 husos. ${ }^{60}$

Por aquellas fechas la escasez de algodón era ya muy aguda. El 30 de enero de 1843 el industrial escribió al prefecto de la ciudad de Puebla, manifestándole que tan sólo contaba con algodón para ocho días. ${ }^{61}$

La reducida oferta algodonera y el alto precio de la fibra condujeron a Estevan de Antuñano a moverse en dos planos distintos. Por un lado, trató de convencer a Antonio López de Santa Anna, a la sazón el hombre fuerte del país, que permitiera la libre importación de algodón en rama. Por otra parte, incrementó sus relaciones con especuladores y agiotistas, que poseían algodón u obtenían permisos para importarlo, convirtiéndose progresivamente en su rehén. Del primer asunto nos ocuparemos en el siguiente apartado, dejando para el epílogo el tratamiento del segundo.

\section{El industrial y el caudillo}

[Santa Anna!, imexicano ilustre! Tres acciones se remarcan en vuestro blasón: cooperasteis a las independencias, sacudisteis la incauta dominación doméstica; vencisteis en Tamaulipas por segunda vez la detestable tiranía extraña. . . habéis sido postulado por los pueblos para poneros a la cabeza de ellos, para regirlos, para hacerlos felices: ardua es la empresa, pesada es la carga; pero vuestro entendimiento es despejado, vuestro brazo fuerte y vuestro carácter eficaz: nada es imposible al hombre cuando procura los medios. Levantad a vuestra patria del polvo; limpiadle las deformidades que en su abyección ha contraido; dadle dignidad; reunid a vuestros hijos dispersos, y ponedlos en la carrera de la felicidad: hay un recurso infalible para conseguirlo, éste es, la ocupación útil y honesta de todos los mexicanos. . .62

Con estas palabras llenas de esperanza y escritas a principios de 1833, Estevan de Antuñano manifestaba su beneplácito ante la postulación de Santa Anna para la presidencia de la república. En el mismo texto, líneas atrás, el industrial, había realizado una exposición sucinta de las ventajas que traería para el país el cultivo y, sobre todo, la elaboración de manufacturas de algodón. Antuñano creía

59 Bazant, "Estudio...", p. 72 e "Industria. . ", p. 141.

60 Antuñano, Documentos. ., p. 7 y anexo (DHIM, vol. 1, p. 513). En el enlistado de las fábricas textiles poblanas, Antuñano aparece como el único propietario de La Constancia Mexicana y a Gumesindo Saviñón, su antiguo socio, se le atribuye la propiedad del Molino del Mayorazgo.

61 Cảrta de Antuñano a José Juan Llufrío, Puebla, 30 de enero de 1843, Antuñano, Documentos..., p. 9 (DHIM, vol, 1, p. 515).

62 Antuñano, Primer asunto de la patria el algodón, Imprenta del Hospital de San Pedro, Puebla, 1833, pp. 19-20 (DHIM, vol. 1, pp. 23-24); Hale, op. cit., p. 238, resalta el pragmatismo político de Antuñano. 
indispensable para la materialización de su proyecto industrial consolidar un gobierno fuerte y legítimo, que resolviera las disputas internas y encaminara al país en la senda del progreso económico. El industrial, sin duda, estaba cabalmente convencido de que el caudillo veracruzano reunía los atributos necesarios para alzarse con el liderazgo nacional. Movido por tal certeza, Antuñano acudió a Santa Anna cuando encontró obstáculos en la expansión de sus negocios.

Cuando se agudizó el problema de la escasez de algodón, Antuñano recurrió primero a Lucas Alamán - con quien había tenido una relación estrecha desde que se había constituido el Banco de Avío- y después, en medio de la desesperación, a Santa Anna. Es así que en el año de 1843, el industrial residente en Puebla dirigió varias cartas al caudillo veracruzano solicitándole, hasta aturdirlo, que permitiera la importación de algodón. En una de ellas (Puebla, 8 de enero de 1843) el fabricante decía al militar:

En fin, mi apreciable amigo, yo sé que $V$. por la misma grandeza de alma que lo asiste, y por ciertas simpatías, está acorde con mis opiniones; y por eso le suplico, con el mayor encarecimiento, que confíe de ellas, y yo le garantizo con mi honor y con mi vida, que los buenos resultados por el bien público y para el honor de $V$. son infalibles, sólo con que levante la ley perniciosísima que prohíbe la introducción de algodón extranjero en rama; porque sus efectos, para hacer progresar la industria nacional de algodones en toda su extensión, son tan contrarios a los que debiera producir la introducción de manufacturas, como lo que diste de comer a tirarse con los platos, con el fin de conservar y robustecer el cuerpo humano: suplico a V. me dispense el símil. ${ }^{63}$

Santa Anna, que en los años anteriores había cultivado una buena relación con los industriales poblanos, tenía que cuidar sus estrechos lazos con los cosecheros veracruzanos de algodón, quienes conformaban parte de su base social. Jan Bazant, incluso, ha esbozado la idea de que el propio Santa Anna fuese un importante cosechero de algodón. ${ }^{64}$ Por tales motivos, el militar respondió cauteloso (Manga de Clavo, 14 de enero de 1843):

Yo celebraré mucho que el gobierno tome en consideración las medidas que $V$. propone, y que dicte providencias benéficas y capaces de lograr el objeto que se desea; en cuyo asunto siento no poder obsequiarlo, porque V. sabe, que separado de los negocios del gabinete como estoy, no debo injerirme en ellos; mucho más cuando la resolución de tan delicado punto, está reservada únicamente a las personas que se hallan a la cabeza del gobierno. ${ }^{65}$

En este tono continuó el intercambio epistolar. El 15 de enero Antuñano manifestó su satisfacción por el nombramiento de Lucas Alamán como director de industria y volvió a la carga con el asunto del algodón al afirmar que "sólo la baratura y abundancia segura del algodón, puede garantizar el espíritu emprendedor para que este

63 Carta de Antuñano a Antonio López de Santa Anna, Puebla, 8 de enero de 1843, Antuñano, Economía política. Documentos (en doce cartas) para la historia de la industria moderna de algodones en México, Imprenta Antigua en el Portal de las Flores, Puebla, 1843, pp. 3-4 (DHIM, vol. l, pp. 525-526).

64 Bazant, Antonio. .., p. 34.

65 Carta de Santa Anna a Antuñano, Manga de Clavo, 14 de enero de 1843; Antuñano, Economia política. Documentos..., p. 5 (DHIM, vol. 1, p. 527). 
ramo de industria importe 15 o 20 millones de pesos a la vuelta de cuatro o cinco años". ${ }^{66}$ Santa Anna, por su parte, concluyó su carta de respuesta diciendo: "mucho estimo sus afanes en bien de la industria y de la felicidad del país. Sea $V$. incansable en tan honrosa ocupación. . ."67

Al no obtener compromiso alguno por parte de Santa Anna, el industrial formuló una solicitud más modesta: que "cuando el algodón del país exceda en Veracruz el precio de 22 pesos quintal, pues mi fin principal es suspender el monopolio, automáticamente el gobierno autorice su importación". ${ }^{68}$ Tres días después, Antuñano declaraba angustiado que en Puebla "no existe ni un solo tercio de algodón en venta" y, el 29 del mismo mes, ofrecía una "escritura pública, comprometiendo en ella mi honor y mi vida, si a la vuelta de cuatro o cinco años no importan las manufacturas de algodón del país 15 o 20 millones de pesos". ${ }^{69}$ Pero el caudillo se salió por peteneras al contestar: "como actualmente estoy separado del gobierno, no puedo tomar ninguna de las providencias que $V$. me propone; pero mi digno sustituto el Sr. Bravo, determinará lo que considere arreglado a justicia, y al interés de todas las clases". ${ }^{70}$

El 7 de febrero Antuñano fue más lejos y planteó con audacia al militar:

Ojalá que $V$. diese un paseo violento a México, y que tomando, aunque fuese por un momento, las riendas del gobierno, echase abajo la perniciosa ley, único obstáculo que se presenta a los grandes avances de la industria algodonera mexicana, fabril y agrícola, y no dude $\mathrm{V}$. que por este hecho iría mereciendo cada día más renombre; porque de una vez arrancada la venda de los ojos ciegos nacionales, destruía todas las maquinaciones de la politica extraña, y cambiaba de un golpe el ser de México. ${ }^{71}$

En su respuesta, por fin, Santa Anna otorgó esperanzas al fabricante cuando aseguró: "muy pronto estaré yo en la capital, adonde voy a encargarme del mando supremo, y desde allí seguiré impartiendo toda la protección del gobierno a esas empresas que hoy constituyen gran parte de la riqueza nacional. .."72 Antuñano, por su parte, se manifestó complacido con las promesas del militar; ${ }^{73}$ pero, en otra misiva, expresó su temor ante la posibilidad de que no se abriera plenamente la importación de algodón y, por tanto, recomendó al presidente provisional: "admita mi consejo de no dar sino en último caso, permisos parciales para introducir algodones, pues

66 Carta de Antuñano a Santa Anna, Puebla, 15 de enero de 1843; Antuñano, Economía política. Documentos. ., pp. 6-7 (DHIM, vol. 1, pp. 528-529).

67 Carta de Santa Anna a Antuñano, Manga de Clavo, 20 de enero de 1843; Antuñano, Economía política. Documentos..., p. 8 (DHim. vol. 1, p. 530).

68 Carta de Antuñano a Santa Anna, Puebla, 22 de enero de 1843, Antuñano, Economia política. Documentos..., p. 8 (DHIM, vol. 1, p. 530).

69 Cartas de Antuñano a Santa Anna, Puebla, 25 y 29 de enero de 1843, Economía politica. Documentos..., pp. 9-11 (DHIM, vol. 1, pp. 531-533).

70 Carta de Santa Anna a Antuñano, Manga de Clavo, l de febrero de 1843; Antuñano, Economía política, Documentos. ., p. 12 (DHIM, vol. 1, p. 534).

71 Carta de Antuñano a Santa Anna, Puebla, 7 de febrero de 1843; Antuñano, Economía política. Documentos..., p. 13 (DHIM, vol. 1, p. 535).

72 Carta de Santa Anna a Antuñano, Manga de Clavo, 18 de febrero de 1843; Antuñano, Economía política. Documentos..., p. 14 (DHim, vol. 1, p. 536).

73 Carta de Antuñano a Santa Anna, Puebla, 8 de marzo de 1843; Economía política. Documentos..., pp. 16-18 (DHIM, vol. 1, pp. 538-540). 
este hecho, dejará muy desigual la suerte de las fábricas para obtener los algodones que necesitan. . ."74

Cual presagio, el temor de Antuñano se cumplió. El 12 de abril de 1843, Santa Anna otorgó un permiso exclusivo a la sociedad Agüero, González y Cía., cuyo apoderado era Manuel Escandón, para importar 60000 quintales de algodón. Posteriormente, la citada compañia traspasó la concesión a Cayetano Rubio, quien recibió haciia finales de año otro permiso para introducir al país 20000 quintales de algodón. Es posible que el propio Santa Anna fungiera como socio de Cayetano Rubio. ${ }^{75}$

No obstante que la medida adoptada por Santa Anna no se ajustaba plenamente a lo propuesto por Antuñano, éste declaró públicamente:

Debidamente doy a $\mathrm{V}$. las gracias por mí y por la industria nacional, por esa disposición [. . . ], pues si bien ella es muy insuficiente para asegurar la conservación de la totalidad de las fábricas existentes [. . . ], y garantizar el espíritu emprendedor para otros establecimientos de la misma clase, lo cual es interesantísimo, siquiera se prueba la ilustración y el celo patriótico con que la presente administración pública de México ha visto esta gran cuestión. . .76

Año y medio después Antuñano escribió al caudillo; agradeció de nueva cuenta los volúmenes de algodón que se habían importado el año anterior y solicitó una vez más: “que entre el algodón extranjero en rama perpetuamente, pagando sólo un derecho de 4 pesos quintal. . "77 Utilizando la insistencia como técnica persuasiva, el fabricante pidió en noviembre de 1844 "que se diesen permisos para algodón en rama a cuantos los pidiesen. . ."78 Santa Anna nunca atendió su solicitud.

Al iniciarse el año de 1845, el departamento de Puebla lanzó una iniciativa para que se autorizara la importación de algodón en rama. ${ }^{79}$ Antuñano y otros industriales insistieron frecuentemente para que se permitiera la introducción de la fibra. El 4 de octubre del mismo año se promulgó el nuevo Arancel General de Aduanas Marítimas y Fronteras y, una vez más, la suerte les fue adversa al ratificarse la prohibición. ${ }^{80}$

Santa Anna dejó a su suerte a las fábricas textiles y sus propietarios tuvieron que sortear grandes obstáculos. El saldo de esos años difíciles fue la progresiva subordinación de la naciente industria a los intereses y designios de los dueños del capital comercial y usura-

74 Carta de Antuñano a Santa Anna, Puebla, s.f.; Antuñano, Economía política. Documentos. ., p. 18 (DHIM, vol. 1, p. 540).

75 Bazant, Antonio. .., p. 32; Potash, op. cit., p. 211.

${ }^{76}$ Carta de Antunano a Santa Anna, Puebla, 5 de mayo de 1843, Diario del Gobierno de la República Mexicana, México, 23 de mayo de 1843, p. 1 (DHIM, vol. 2, p. 29).

77 Carta de Antuñano a Santa Anna, Puebla, 22 de septiembre de 1844, El Mercurio Poblano, Puebla, 12 de octubre de 1844, p. 1 (DHIM, vol. 2, p. 67).

78 Carta de Antuñano a Santa Anna, Puebla, 20 de noviembre de 1844 (DHIM, vol. 2, p. 316).

${ }^{79}$ El Mercurio Poblano, Puebla, 22 de febrero de 1845, pp. 2-3 (Dнiм, vol. 2, p. 316).

so Dublán y Lozano, op. cit., vol. 5, pp. 42-44. 
rio: los agiotistas. ${ }^{81} \mathrm{El}$ destino final de los establecimientos fabriles de Estevan de Antuñano ilustra con claridad este proceso general.

\section{Epílogo}

En marzo de 1844, Antuñano contaba a Lucas Alamán que cinco de las 18 fábricas poblanas de hilados de algodón habian cerrado sus puertas y varias más estaban a punto de hacerlo. ${ }^{82}$ Las factorías más poderosas, o las que podían obtener algodón a precios razonables, eran las que tenían posibilidad de sobrevivir. Por otra parte, el acceso a la fibra estaba mediado por la intervención de comerciantes y especuladores, quienes podían adelantar a los cosecheros la compra de sus siembras o traficar con el gobierno la obtención de permisos de importación. Conocidos agiotistas como Cayetano Rubio, Manuel Escandón, Francisco Yturbe y Pedro Berges de Zúñiga, figuraban entre quienes proveían de algodón a Estevan de Antuñano.

Durante el año de 1844 Estevan de Antuñano mantuvo una correspondencia regular con Cayetano Rubio, la cual da razón de la precariedad en que vivía la industria textil. El 20 de marzo, el fabricante se quejó del alto precio del algodón que le ofrecía en venta el especulador y de la pretensión de que lo adquiriera al contado. ${ }^{83}$ Posteriormente, Antuñano propuso pagarlo en un plazo de cinco o seis meses. ${ }^{84}$ Para mayo, el industrial ofreció saldar su adeudo enviando semanalmente determinadas cantidades de manta, "pues es a Dios gracias casi mi único objeto en este tiempo el pagar a $V$ "' ${ }^{85}$ Tres meses después, Antuñano ofreció a Rubio comprarle 2000 quintales de algodón, pagaderos en un plazo de ocho meses. ${ }^{86}$ La correspondencia fluía y la angustia del fabricante aumentaba. El 12 de junio escribió con resentimiento:

. . aunque $V$. es mi amigo y me dio promesas de consideración en circunstancias críticas y también pruebas dio de conocer mi posibilidad pecuniaria y mi carácter ahora me estrecha demasiado después que me puso unos plazos cortísimos para tan grandes sumas. . ningún motivo tiene $V$. para tacharme como informal y mal pagador y a esto sólo ha dado lugar el procedimiento en estos particulares de algodones un gobierno tan lleno de ignorancia como indiferencia por la prosperidad de la industria y de su fundador. . .87

El 26 de junio, Antuñano manifestó que perdía de tres a cuatro reales en cada pieza de mànta que enviaba a Cayetano Rubio. ${ }^{88}$ En

81 Margarita Urías, "Militares y comerciantes en México, 1828-1846: las mercancías de la nacionalidad", Historias, INAH, núm. 6, abril-julio de 1984, pp. 49-70; Rosa Ma. Meyer, "Empresarios, crédito y especulación (1820-1850)", en Leonor Ludlow y Carlos Marichal (comps.), Banca y poder en México (1800-1925), Editorial Grijalbo, México 1986, pp. 99-118.

82 Carta de Antuñano a Alamán, 31 de marzo de 1844 (DHIM, vol. 2, p. 562).

83 Carta de Antuñano a Cayetano Rubio, 20 de marzo de 1844 (DHIM, vol. 2, p. 102).

84 Carta de Antuñano a Rubio, 27 de marzo de 1844 (DHIM, vol. 2, p. 114).

${ }^{85}$ Carta de Antuñano a Rubio, 19 de mayo de 1844 (DHIM, vol. 2, p. 176).

86 Carta de Antuñano a Rubio, 22 de mayo de 1844 (DHIM, vol. 2, p. 181).

87 Carta de Antuñano a Rubio, 12 de junio de 1844 (DHIM, vol. 2, p. 207).

88 Carta de Antuñano a Rubio, 26 de junio de 1844 (DHIM, vol, 2, p. 222). En julio Antuñano intentó comprar algodón a Manuel Escandón. Carta de Antuñano a Escandón, 19 de julio de 1844 (DHIM, vol. 2, pp. 241-242). 
septiembre reconoció que el especulador lo tenía en sus manos y le propuso a éste otro trato para que lo siguiera abasteciendo de algodón. ${ }^{89}$ Hacia finales del año, el fabricante denunció ante la junta general directiva de la Dirección General de Industria el "plan de destrucción" de la industria de hilados y tejidos de algodón diseñado por Cayetano Rubio. ${ }^{90}$ Todo parece indicar que los esfuerzos realizados por Antuñano para quitarse las ataduras del especulador fueron infructuosos.

Pero los compromisos del fabricante no se reducían a su adeudo con Cayetano Rubio. Otros agiotistas lo tenían comprometido. Es así que en febrero de 1845, Antuñano escribió a Francisco Yturbe pidiéndole un préstamo en efectivo a cambio de la hipoteca de una de sus fábricas (La Economía Mexicana): “mi objeto en esta solicitud es el pagar de un golpe todo lo que debo y quitarme de las molestias que me causan los monopolios del algodón y los fabricantes: el primero porque prosiguió sus especulaciones. . . y los segundos porque doy barato y no fío". ${ }^{91}$

Pero el industrial continuaba hundiéndose. En junio de 1845 comunicó a Lucas Alamán su decisión de parar dos terceras partes de los husos de sus fábricas, "hasta que consiga algodones a precios y plazos correspondientes a proporcionarme alguna utilidad y no trabajar sólo para los especuladores de algodón"'.92 Sin embargo, contra su voluntad, siguió trabajando para ellos.

Al parecer, el mayor acreedor de Estevan de Antuñano era un agiotista francés de nombre Pedro Berges de Zúñiga. Durante 1845, el fabricante recibió del francés varios envios de algodón a crédito (que tenían un valor de 100000 pesos) y dinero en efectivo (24 837)..$^{93}$ Con el transcurso del tiempo las cuentas se complicaron y el fabricante no lograba saldar el adeudo. Como garantía de pago del algodón recibido, el industrial hipotecó a Berges su fábrica más importante: La Constancia Mexicana. Las subsecuentes deudas las fue incorporando:

. . a la escritura por la cual hipotequé a V. mi fábrica Constancia Mexicana la que a nadie debe más que a V. sólo no obstante que vale millón y medio de pesos y que se halla en el más perfecto estado de obra como V. bien sabrá y verá por los dos adjuntos estados de las semanas anteriores que le estimaré me devuelva. ${ }^{94}$

Para enero de 1846, cuando el general Mariano Paredes y Arrillaga permitió temporalmente importar algodón por las aduanas de San Blas y México (con un impuesto de diez pesos por quintal), Antuñano estaba en las garras de los agiotistas. Cuando murió, al año siguiente, Pedro Berges de Zúñiga se convirtió en el principal acreedor de su testamentaría. En 1847 se realizó el concurso a los bienes consignados en ésta y se otorgó al francés la hacienda de La

89 Carta de Antuñano a Rubio, 3 de septiembre de 1844 (DHIM, vol. 2, pp. 296-297).

90 Carta de Antuñano a Alamán, 26 de diciembre de 1844 (DHIM, vol. 2, p. 580).

91 Carta de Antuñano a Francisco Yturbe, 21 de febrero de 1845 (DHIM, vol. 2, p. 363).

92 Carta de Antuñano a Alamán, 27 de junio de 1845 (DHIM, vol. 2, p. 598).

93 Aguirre y Carabarín, op. cit., p. 188.

94 Carta de Antuñano a Pedro Berges de Zúñiga, 18 de junio de 1845 (DHIM, vol. 2, pp. 461-464). 
Noria, el molino de Santo Domingo y La Economía Mexicana. En la década de los sesenta, por la misma vía, Berges se hizo de La Constancia Mexicana y de la hacienda de Santo Domingo. ${ }^{95}$

La historia de la empresa industrial de Estevan de Antuñano da cabal razón de los obstáculos económicos y políticos que sufrió la producción de manufacturas textiles durante la primera mitad del siglo xIx. En un principio, la competencia de los artículos extranjeros dificultó su desarrollo. Superado parcialmente este escollo (ya que el contrabando siempre estuvo presente) con la ley prohibicionista de 1837, la industria padeció el desabasto de algodón. Este hecho expresaba, por una parte, el desarrollo desigual de la economía mexicana, al convivir una agricultura tradicional no tecnificada con un sector industrial moderno, obstaculizando la primera el desarrollo del segundo y, por la otra, la imposibilidad del Estado de mantener un proyecto industrial a largo plazo. La dificultad de los distintos gobiernos para establecer hegemonías duraderas y de alcance nacional (lo que no hacía sino manifestar la precariedad de sus bases sociales), complicaba en extremo la ejecución de un proyecto industrial durable. Por último, resultaba indudable que dentro del conjunto de los capitalistas, comerciantes y agiotistas constituían el sector más poderoso, subordinando al débil núcleo de los industriales. El destino de las fábricas de los padres de la industria textil nacional (Antuñano y Alamán), constituye, sin duda, un ejemplo elocuente. 